\title{
Electrochemical Corrosion Behaviour of Carbon Steel in Concrete with Metakaolin Admixture Exposed to Soil with High Concentration of Chloride Ions
}

\author{
Zhiqiang Xing ${ }^{1}$, Dongpo He ${ }^{1, *}$, Hongguang Wang ${ }^{1}$, Zhifeng Ye $^{2}$, Shoucheng Yang ${ }^{3}$ \\ ${ }^{1}$ School of Civil Engineering, Northeast Forestry University, Harbin 150040, China \\ ${ }^{2}$ Heilongjiang Province Highway Undertaking Development Center, Harbin 150001, China \\ ${ }^{3}$ Harbin Engineering Quality Consulting Center, Harbin 150010, China \\ *E-mail: hedongp11@sina.com
}

doi: $10.20964 / 2021.03 .10$

Received: 15 October 2020 / Accepted: 18 December 2020 / Published: 31 January 2021

\begin{abstract}
One of the most useful construction materials is concrete. Cementitious materials blended with some admixtures have been used to improve durability, sustainability and reduction of production cost. In recent years, the use of metakaolin as one the most efficacious pozzolans in concrete has received remarkable interest. On the other hand, chloride ions in different environments play a significant role in corrosion reaction. To evaluate the effects of soil environment, especially the soil with high concentration of chloride ions on the corrosion of carbon steel in concrete with metakaolin admixture, investigations were carried out. In this study, electrochemical corrosion behavior of carbon steel in concrete with metakaolin replacement in different ratios (5 wt $\%, 10 \mathrm{wt} \%, 15 \mathrm{wt} \%$ and $20 \mathrm{wt} \%$ ) was discussed. Electrochemical corrosion behavior was studied by monitoring of corrosion potentials, polarization measurement and electrochemical impedance spectroscopy (EIS) and also the surface morphology was studied by scanning electron microscopy (SEM). EIS results indicated that the concrete containing metakaolin, especially the sample with $15 \mathrm{wt} \% \mathrm{MK}$ revealed higher corrosion resistance compared to the ordinary Portland cement (OPC). Furthermore, polarization measurements showed that the lowest corrosion current density and the highest corrosion potential belonged to the $15 \mathrm{wt} \% \mathrm{Mk}$ sample which was consistent with EIS results. Scanning electron microscopy revealed that the mixture containing $15 \mathrm{wt} \% \mathrm{MK}$ is denser and more uniform with less porosity than that of the OPC sample.
\end{abstract}

Keywords: Corrosion resistance; Electrochemical Impedance spectroscopy; Metakaolin; Polarization; Carbon steel in concrete mixtures

\section{$\underline{\text { FULL TEXT }}$}

(C) 2021 The Authors. Published by ESG (www.electrochemsci.org). This article is an open access article distributed under the terms and conditions of the Creative Commons Attribution license (http://creativecommons.org/licenses/by/4.0/). 